\title{
Effects of age and IQ on rate of learning and pattern of acquisition of lists of trigrams'
}

\author{
ARNOLD B. WOOdRUfF AND N. L. PIELSTICK
} NORTHERN ILLINOIS UNIVERSITY

\begin{abstract}
Abstraet
Sixty Ss, from three age and two IQ levels, learned two 10-item lists of CVC trigrams, representing high and low association values. Both variables had significant effects on the rate of learning, but there was no significant interaction of them. On the low association value list, it was found that there was a significant interaction between IQ level and the pattern of acquisition of the syllables.
\end{abstract}

\section{Problem}

Studies do not agree on the relationship of IQ and age on learning in children. Ellis et al (1960) reported two studies in which mental retardates, normals and superior Ss were compared on learning a serial list on 10 nouns and a finger maze. In the verbal learning study there was a significant difference in the rates of learning between adjacent groups, but on the finger maze problem there was a significant difference between the retardates and normals only. Eisman (1958) used three IQ groups similar to those used by Ellis et al, and had them learn three lists of paired-associate pictures, each representing a different level of meaningfulness. There were no significant differences between groups on the speed of learning, retention or stimulus generalization. Akutagawa \& Benoit (1959) had two age levels, with two IQ groups at each, learn pairedassociate pictures. They found significant differences in learning between age levels, but not between IQ groups. In none of these studies was there an attempt to compare how the groups progress through the learning sequence. The present study was designed to investigate the effects of age and IQ on the rate of learning lists of CVC trigrams; also, to find the effects of these variables on the pattern by which the syllables are acquired.

\section{Subjects}

The Ss were 3rd, 5th, and 7th grade children from two IQ groups, "average" (Binet IQ, 90-110) and "gifted" (Binet IQ, 130 or above). The total N was 60, with 10 in each sub-group.

\section{Procedare}

The Ss learned two 10-item lists of CVC trigrams which did not spell words, representing two levels of association value (15\% and $85 \%)$ according to the Archer (1960) norms. These were presented to the $S$ individually, using a stoelting memory-drum at a $2 \mathrm{sec} . / 2 \mathrm{sec}$. rate of presentation, with an $8 \mathrm{sec}$. intertrial interval. The list with the higher association level was learned first and a 5-min. rest period was introduced between lists. The anticipation method was

\begin{tabular}{|c|c|c|c|c|c|c|}
\hline \multirow[b]{2}{*}{ Grade } & \multicolumn{6}{|c|}{$\begin{array}{l}\text { TABLE I } \\
\text { RIALS TO REACH GRITERION }\end{array}$} \\
\hline & & 3 & & 5 & & 7 \\
\hline A.bility Level & A & G & A & G & A & $G$ \\
\hline High Assoc. List & 24.9 & 17.0 & 19.8 & 10.8 & 15.8 & 9.1 \\
\hline Low Assoc. List & 37.2 & 30.0 & 33.2 & 17.7 & 27.6 & 14.7 \\
\hline
\end{tabular}

used, with the $S$ being required to spell the syllable. The criterion of learning was one perfect trial through the list.

Results and Discussion

Table 1 gives the mean numbers of trials for each group to reach criterion on the lists. For both lists there were significant effects (for all, $p<.001$ ) of both grade level and ability level on the rate of learning. For the high association list the F-ratios were 8.27 and 20.75, respectively; for the low association list, 9.90 and 28.25, respectively. An examination of Table 1 shows that for both lists the gifted group at each grade level learned more quickly than the average group of the next higher grade level tested. In general these findings agree with those of Ellis et al (1960) regarding the effects of mental ability on learning a list of verbal symbols; but do not agree with those of Eisman (1965) and Akutagawa \& Benoit (1959) who found no effect of IQ on learning paired-associates. This latter study did find differences between age levels, as was found in the present study. Perhaps the lack of agreement noted can be traced to the difference between the learning tasks.

Tables 2 and 3 show the mean number of trials for each group to acquire the syllables of the lists.

TABLE 2

MEAN NUMBER OF TRIALS FOR EACH GROUP TO ACQUIRE EACH SYLLABLE IN THE HIGH ASSOCIATION LIST

\begin{tabular}{ccrrrrrr} 
Grade & \multicolumn{2}{c}{3} & \multicolumn{2}{c}{5} & \multicolumn{2}{l}{7} \\
\hline Ability Level & A & G & A & G & \multicolumn{1}{c}{ A } & G \\
\hline \hline Position & Syllable & & & & & & \\
\hline 1 & MON & 6.4 & 2.7 & 4.5 & 2.1 & 2.2 & 2.4 \\
2 & KAD & 13.7 & 8.9 & 13.6 & 5.1 & 8.1 & 3.9 \\
3 & SIC & 16.1 & 11.1 & 13.8 & 5.3 & 10.6 & 4.1 \\
4 & PUF & 19.7 & 13.3 & 15.3 & 7.7 & 9.6 & 5.8 \\
5 & WIS & 19.1 & 13.6 & 14.9 & 7.8 & 9.9 & 6.8 \\
6 & GEL & 19.0 & 12.6 & 13.4 & 7.6 & 13.3 & 5.1 \\
7 & BAK & 21.4 & 13.4 & 17.6 & 9.9 & 14.9 & 7.8 \\
8 & JIF & 18.7 & 11.9 & 14.1 & 7.9 & 11.7 & 5.8 \\
9 & CYN & 21.0 & 10.2 & 15.5 & 6.4 & 9.3 & 3.8 \\
10 & NAH & 20.0 & 9.9 & 14.0 & 5.7 & 8.1 & 4.5
\end{tabular}


TABLE 3

MEAN NUMBER OF TRIALS FOR EACH GROUP TO ACQUIRE EACH SYLLABLE IN THE LOW ASSOCIATION LIST

\begin{tabular}{lllllll} 
Grade & & 3 & & 5 & & 7 \\
\hline Ability Level & A & G & A & G & A & G \\
\hline
\end{tabular}

\begin{tabular}{ccrrrrrr}
\hline \hline \multirow{2}{*}{ Position } & \multicolumn{1}{l}{ Syllable } \\
\hline 1 & CIJ & 15.5 & 12.0 & 15.5 & 4.0 & 4.9 & 3.3 \\
2 & VYK & 26.5 & 18.5 & 26.3 & 9.3 & 13.5 & 6.6 \\
3 & ZUF & 32.7 & 21.1 & 27.6 & 10.9 & 18.5 & 10.3 \\
4 & QEZ & 34.4 & 22.9 & 28.8 & 14.5 & 18.4 & 10.9 \\
5 & XOM & 33.4 & 16.2 & 20.8 & 9.8 & 15.2 & 6.5 \\
6 & KIH & 33.3 & 21.6 & 28.4 & 12.2 & 21.6 & 12.6 \\
7 & WYJ & 35.7 & 25.1 & 31.0 & 15.5 & 25.2 & 13.2 \\
8 & FEP & 33.2 & 17.5 & 26.7 & 12.8 & 22.2 & 6.3 \\
9 & BIW & 30.0 & 15.8 & 21.7 & 10.9 & 15.3 & 5.2 \\
10 & GYQ & 35.8 & 25.4 & 31.1 & 12.0 & 25.0 & 8.8
\end{tabular}

Acquisition means that the learner made no further errors on that syllable until he reached criterion, so the acquisition trial for that syllable was the first trial after the last error. The analysis of variance (Lindquist, 1953, pp. 281-284) for the high association list indicated that syllable position accounted for a significant amount of variance $(F=27.37 ; p<.001)$, as an association-inhibition hypothesis would suggest, but there was no significant interaction between syllable position and either grade or ability level. However, in the low association list not only was the variance attributed to syllable position significant $(F=18.24$; $p<.001$ ), but there was a significant interaction between syllable position and ability level $(F=3.59$; $p<.001)$. A further examination of Table 3 shows that on the low association list only the 5th and 7th grade gifted groups showed an acquisition pattern of the nature suggested by Hull (1935), while the other groups showed no differences between the number of trials to acquire the syllables at the end of the lists and those in the middle. Table 2 will show a similar but not as pronounced a trend for the high association list. This seems to indicate that the association-inhibicion effects on serial learning are affected by the ability level of the learner and that the patterns of acquisition of a list of syllables will vary according to the ability level of the learner.

This difference in acquisition pattern may be a function of mental development and the gifted (higher ability) individuals achieve this point sooner. The level of verbal development of the learner may have an effect. However, this would be tied closely to the degree of meaningfulness and Shapiro (1964) has suggested that with age there is a difference in the degree of meaningfulness of CVC trigrams, but that the individual trigram remains fairly stable in its meaningfulness relationship to other trigrams. Thus, on this basis one would not predict the difference in acquisition patterns found here, although it must be recognized that Shapiro did not use nonsense trigrams but ones that spelled words.

\section{References}

Akutagawa, D., \& Benoit, E. D. The effect of age and relative brightness on associative learning in children. Child Develpm., $1959,30,229-238$.

Archer, E. J. A re-evaluation of the meaningfulness of all possible CVC trigrams. Psychol. Monogr., 1960, 74, No. 10 (Whole No. 497).

Eisman, Bernice S. Paired associate learning, generalization and retention as a function of intelligence. Amer. J. ment. Defic., 1958, 63, 481-489.

Ellis, N. R., Pryer, Margaret W., Distefano, M. K., \& Pryer, R. S. Learning in mentally defective. normal, and superior children. Amer. J. ment. Defic., 1960, 64, 725-734.

Hull, C. L. The conflicting psychologies of learning-a way out. Psychol. Rev., 1935, 42, 491-516.

Lindquist, E. F. Design and analysis of experiments in psychology and education. Boston: Houghton Mifflin Co., 1953.

Shapiro, Sydelle S. Meaningfulness values of $52 \mathrm{CVCs}$ for gradeschool-aged children. Psychon. Sci., 1964, 1, 127-128.

Notes

1. This study was supported by the Illinois Special Study Project for Gifted Children. 